Преводна статия от Европейското списание по болнична фармация, публикувана с разрешение на Европейската асоциащия на болничните фармацевти (ЕАНР)

The original source of this article is: Linda J Dodds. Optimising pharmacy input to medicines reconciliation at admission to hospital: lessons from a collaborative service evaluation of pharmacy-led medicines reconciliation services in 30 acute hospitals in England

Eur J Hosp Pharm 2014;21:95-101 doi:10.1136/ejhpharm-2013-000385

\title{
OPTIMISING PHARMACY INPUT TO MEDICINES RECONCILIATION AT ADMISSION TO HOSPITAL: LESSONSFROM A COLLABORATIVE SERVICE EVALUATION OFPHARMACY-LED MEDICINES RECONCILIATION SERVICES IN 30 ACUTE HOSPITALS IN ENGLAND
}

\author{
Linda J Dodds \\ Medicines Use and Safety Division, East and South East England Specialist Pharmacy Services, Clinical \\ Pharmacy Unit, Northwick Park Hospital

\begin{abstract}
ОПТИМИЗИРАНЕ НА РОЛЯТА НА ФАРМАЦЕВТИТЕ В ПРОЦЕСА НА ЛЕКАРСТВЕНО СЬГЛАСУВАНЕ ПРИ БОЛНИЧЕН ПРИЕМ: ИЗВОДИ ОТ СЬВМЕСТНО ОЦЕНЯВАНЕ НА УСЛУГА, ИЗВЬРШВАНА
\end{abstract} \\ ОТ ФАРМАЦЕВТИ В 30 БОЛНИЦИ ЗА АКТИВНО ЛЕЧЕНИЕ В АНГЛИЯ
}

\author{
Линда Дж. Додс \\ Дирекиия за лекарствена употреба и безопасност, Източна и Югоизточна Англия \\ Специалист фармацевтични услуги, Отдел клинична фармация, Болница Нортуик парк
}

\begin{abstract}
Резюме.
Цел: Сравняване на приноса на болничните фрармацевти в поцеса на лекарствено съгласуване (ЛС, на англ. Medicines Reconciliation) за различни терапевтични области за увеличаване на наличната информация относно предоставянето на услугата.
\end{abstract}

Методи: Аптеките в 30 болници за активно лечение извърииха оценка на своите услуги за ЛС в 10 терапевтични области с помощта на пилотен въпросник за събиране на инорормация. Отчетени бяха случаите на пропуснати лекарствени продукти и несъотвествия поради погрешна дозировка при предписване на лекарства при болничен прием, както и клиничната значимост на тези фрактори. Събрани бяха данни относно характера на хоспитализацията (напр. дали е планирана), броя едновременно назначени лекарства и дали пациентът е носел в болницата лекарствата, които приема у дома.

Резултати: Разгледани бяха 3086 ЛС и 4041 неволни несъответствия (НН, на англ. unintended discrepancies) при предписването на лекарства (средна стойност 1.3/ЛС). 1616 HН (0.52 на пациент) са определени, че са с потенциал за умерено въздействие върху лечението на пациента (Ниво 3). Отчетени бяха НH от III ниво във всички терапевтични области; в секторите „Прием на пациенти“, „Гериатрична грижа“, „Обща хирургия“ и „Ортопедия“ обаче нормата на HH от III ниво беше по-висока в сравнение с пациентите като ияло (двустранен Z тест, 99\% доверителен интервал). Повече НH са отнесени към трето ниво сред пациентите om „Гериатрична грижа“ и „Обща хирургия“ (двустранен Z mест, 99\% доверителен интервал). Над 80\% от отчетените грешки са в четири категории лекарства (за сърдечно-съдова система, централна нервна система, жлези с вътрешна секреция, дихателна система). Плановостта 
на хоспитализацията и наличието на собствени лекарства на пациентите оказват слабо влияние върху прецизността на назначаването на лекарства при болничния прием. Средно ЛС е отнемало 15 минути.

Изводи: Определянето на приоритетността на ЛС, водено от фрармацевти (ЛСФ) единствено на принципа на терапевтична област или вид прием в болница не е подход, обезпечаващ безопасност. Вместо това следва да се търсят мултидисциплинарни методи за прилагане на ЛС, които най-оптимално използват наличната информация.

\section{Abstract.}

Objective: To compare pharmacy team input to medicines reconciliation (MR) in a variety of care areas in order to inform optimisation of service delivery.

Methods: 30 acute hospital pharmacy departments evaluated their MR services in 10 care areas using a piloted data collection form. Omitted medicines and wrong dose discrepancies on the admission prescription were recorded and rated for clinical severity. Data were collected on whether the admission was planned, the number of coprescribed medicines and if the patient had brought their home medicines into hospital.

Results: 3086 MRs were reviewed and 4041 unintended discrepancies (UDs) in prescribing were identified (mean 1.3/MR). 1616 UDs (0.52 per patient) were ranked as having the potential for moderate impact on patient care (Level 3). Level 3 UDs were identified in all care areas; however, Admissions, Care of the Elderly, General Surgery and Orthopaedic patients had more Level 3 UDs per patient than the total population (twotailed Z test, 99\% Cl). More UDs was ranked Level 3 in Care of the Elderly and General Surgery patients (twotailed Z test, $99 \% \mathrm{Cl}$ ). Over $80 \%$ of recorded errors involved four prescribing categories (cardiovascular, central nervous system, endocrine, respiratory). Planned admissions and the presence of the patients' own medicines had little impact on the accuracy of admission prescribing. The average time to carry out MR was $15 \mathrm{~min}$.

Conclusions: Prioritisation of pharmacy-led MR by care area or type of admission alone is not a safe option. Opportunities should instead be taken to explore multidisciplinary methods of implementing MR which optimise available information.

\section{ОБЩА ИНФОРМАЦИЯ}

Установено е, че непълната или неточната комуникация при прием на пациент в болница води до грешки при предписването на лекарства в до $67 \%$ от всички приеми, като между $11 \%$ и $59 \%$ от случаите са клинично значими (1-6). Непоправени, грешките извършени в момента на хоспитализирането, могат да имат последствия в хода на болничния престой на пациента и след изписването, което води до повишен контакт с доставчици на здравни грижи, до повторна хоспитализация или дори до смърт $(7,8)$. В проспективно проучване за измерване на естеството и нормата на грешките при предписване на лекарства от младши лекари в 20 болници в Англия, Dornan et al. установяват, че най-често грешките се случват именно при приема в сравнение с всеки друг момент на [болничния] престой на пациентите (1). Поради тези причини от ключово значение за подобряване на здравните стратегии и за повишаване на качеството в много системи на здравна икономика вече почти 10 годи- ни е прецизното снемане на всички назначени на пациента лекарства в момента на приема в болница. В момента в Англия има движение за утвърждаване на ЛС като национална мярка за безопасността на пациентите.

Институтът за подобряване на здравеопазването (the Institute of Healthcare Improvement) дефинира ЛС по следния начин: „Лекарственото сьгласуване е процесът, при който се прави възможно най-прецизен списък на лекарствените продукти, назначени в дадения момент на пациента, в това число наименование на лекарствения продукт, дозировка и път на въвеждане, като тези лекарства се сравняват със списька лекарства, които пациентът в момента използва, с отчитане на несъответствия и с документиране на промени, и така се постига пълен списък на лекарствата, който се съобщава/ предава точно.“ (9) В Англия националните указания изискват политиките да гарантират „участие на фармацевтите в процеса на ЛС на възможно най-ранен етап след приемането на пациента в 
болничното заведение“ и ,ясно определяне на отговорностите на фармацевтите и другите членове на персонала в процеса на ЛС“ (10). Тези указания са въз основа на систематичен преглед на ефективността на интервенциите за предотвратяване на лекарствени грешки при хоспитализация, в това число ефективността на разходите на интервенциите (11).

Предизвикателствата, свързани с провеждането на прецизни и своевременни ЛС са надлежно отчетени и представляват сьществен проблем за организациите (12).

За да се оцени напредъкът спрямо зададените национални указания беше предприет съвместен преглед за установяване на изходните условия в Източна и Югоизточна Англия през януари 2010 г. Петдесет и шест болници за активно лечение с общо 33120 легла участваха в инициативата. Предмет на оценка бяха 9101 приема в болница за активно лечение. За $87 \%$ от пациентите се проведе ЛСФ, но само при 52\% това се случи в първите 24 часа от хоспитализацията (13). Бяха документирани средно 1.32 неволни несъотвествия на едно ЛС, като в 73\% от случаите е ставало дума за пропуснато лекарство, а в 14\% - за грешна дозировка (14).

След това се предложи извършването на оценка на услугата, за да се определят начини за оптимизиране на нейното предоставяне за максимални ползи за пациента. Целта беше следната:

- Събиране на данни относно резултатите от провежданите от фармацевти ЛС в различни терапевтични области.

- Събиране на данни относно факторите с потенциално въздействие върху качеството на предписването на лекарства при хоспитализация (дефинирано като: общ брой лекарства, изписани на пациент; вид хоспитализация - планова или по спешност; дали пациентът е носел свои лекарства в болницата или не).

\section{МЕтоди}

Установи се, че настоящото мероприятие е оценяване на услуга и не се изисква одобрение във връзка с изследователската етика.

\section{СъБИРАНЕ НА ДАННИ}

Разработи се и се приложи пилотно въпросник за събиране на данни. Бяха поканени за участие болнични аптеки в Източна и Югоизточна Англия, като 30 болници за активно лечение събираха проспективно данни в продължение на три седмици през септември 2010 г. Участниците можеха да избират дали да оценяват всички легла, за които се предлага ЛСФ, или извадка от легла. ЛСФ е следвало стандартната оперативна процедура за услугата на съответното заведение.

Във всяка участваща организация специален координатор интегрираше данните, събрани от болничните фармацевти в отделенията. Интегрираните данни се връщаха на координатора на проекта (автора) за въвеждане в спредшийтове в Ексел.

За всяко ЛС, провеждано от фармацевт, се събираха данни относно: терапевтичната област; неволните несъотвествия (НH) между назначените лекарства преди болничния прием и назначените в болничното заведение лекарства, като тези неволно допуснати несътоветствия са били или пропуснати лекарства (дефинирани като лекарства, приемани преди хоспитализацията, но неотразени в болничния картон или записите за лечението) или лекарства, предписани с погрешна дозировка; времето, необходимо за снемане на ЛСФ. Оценяването на услугата беше ориентирано към несътоветствия заради пропуснати лекарства или погрешна дозировка, поради факта, че тези две категории съставляват 87\% от несъотвествията при проверката, проведена няколко месеца по-рано и поради това, че тези фактори имат ясно въздействие върху лечението на пациента и съответно могат да послужат като позиции, позволяващи сравняване между тези области.

За всяко НН под формата на пропуснато лекарство или погрешна доза, установено в хода на ЛС, се записваха следните данни: клинична категория по Британската национална фармакопея (British National Formulary (BNF)); вид на хоспитализацията - планова или спешна; дали е извършено ЛСФ в рамките на първите 24 часа от хоспитализацията на пациента; дали пациентът е донесъл в болницата със себе си лекарства от дома си; общ брой приемани лекарства, съгласно установеното от ЛСФ (две сатегории: четири или под четири лекарства и пет и над пет лекарства); потенциален клиничен ефект от грешка, свързана с пропуснато в описа лекарство или с грешна дозировка.

Степента на потенциалния клиничен ефект (клинична значимост) на всяко НН се определя от специалиста, провеждащ ЛСФ или посочения за заведението координатор. Определенията на 
въздействието са въз основа на използваните определения в схемата за докладване на инциденти съгласно Националната система за докладване и анализиране (the National Reporting and Learning System for England and Wales) (16):

- I ниво. Без ефект/Несъществен: За пациента не би произтекла вреда.

- II ниво. Нисък/Слаб: За пациента би произтекла минимална вреда. Може да се налага допълнително наблюдение или минимално лечение.

- III ниво. Умерен: Възможно е да доведе до умерено увеличение на лечението със значителна, но не трайна вреда за пациента.

- IV ниво. Сериозен/Тежък: Възможно е настъпването на трайно увреждане.

Бяха представени примери, свързани с употре-

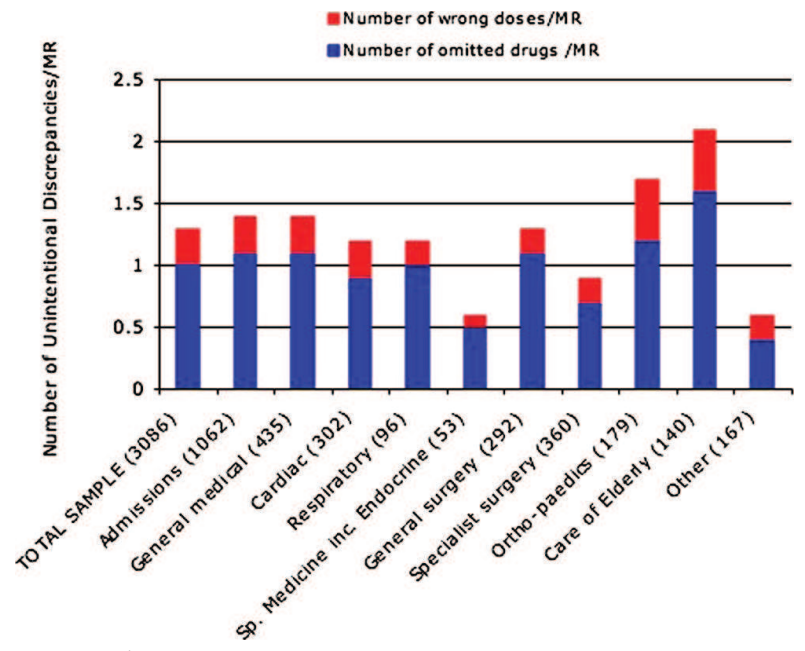

Фигура 1. Брой случаи на установени пропуснати лекарства и на погрешни дозировки за едно ЛС за всяка терапевтична област (в скоби е даден броят преzледани ЛС) спрямо общия брой в извадката (N=3 086).

бата на лекарствени продукти, за да се гарантира, че участниците правят разлика между различните нива потенциална вреда. За всяко НH, определено от участниците като „умерено“ или „,тежко“ (III или IV ниво) се записваха следните реквизити: наименование на лекарството; дали е налице пропуск да се опише лекарственият продукт или грешна дозировка; данни, които биха помогнали за обяснение на нивото на клинична значимост. Решенията за определяне на клиничната значимост не подлежаха на вътрешна ревизия.

\section{АНАЛИЗ НА ДАННИТЕ}

Данните са организирани в 10 терапевтични области (Фигура 1). Специализираните лекарства включват данни от отделенията за ХИВ, онкология, бъбречни, инфекциозни заболявания, нарушения на съня и ендокринни заболявания. Специализираната хирургия включва данни от отделенията гинекология, кардиология и гръдна хирургия, коремна хирургия, трансплантации, урология, съдова хирургия, лицево-челюстна хирургия, изгаряния и очна хирургия. Групата „Други“ обхваща легла в сектори родилен, педиатричен и частен.

Данните за рискови лекарства са разгледани отделно. „Високорискови лекарства“ са лекарствените продукти, подлежащи на национални предупреждения относно безопасността или лекарствени продукти, при които краткотрайно пропускане на прием може да дестабилизира клиничното състояние на пациента. Спъськът включва: варфарин, метотрексат, инсулин, стероиди и имуносупресанти, антиепилептични средства, антипаркинсонови агенти.

Тъй като пациентите са събрани от участниците от най-разнообразни терапевтични области и предвид големия размер на извадките, допускането относно събраните данни е, че те са с нормално разпределение. Приложен е дисперсионен анализ с двустранен Z тест, за да се определи дали са налице значителни различия между броя НН от трето ниво на един пациент във всяка терапевтична група и общия брой разглеждани обекти и дали вероятността за установено НН, потенциално водещо до умерена вреда варира от една терапевтична група до друга.

\section{РезУлтати}

Всички болници избраха да събират данни относно провеждани от фармацевти ЛС в избрани терапевтични области. Най-често разглежданият сектор е секторьт за прием на пациенти (сектор с легла, от който пациентите могат да бъдат изписвани след кратък престой и насочвани към по-специализирано отделение за по-дълъг престой).

Бяха прегледани общо 3086 ЛСФ, като се установиха 4041 случая на пропуснати лекарства и погрешни дозировки. Това представлява средна стойност от 1.3 НН на прегледано ЛСФ. Всички терапевтични области включваха данни от поне осем болници; количеството данни, подадено от отделните заведения обаче за дадена терапевтична област често беше малко, при което в пет от избраните терапевтични области общият брой прегледани ЛСФ беше под 150. Във Фигура 1 е показан броят 

прием: изводи от съвместно оценяване на услуга, извършвана от фармацевти в 30 болници ...

Таблица 1. Общ брой установени неволно пропуснати лекарства и погрешни дозировки по категории по Британската национална фармакопея (БНФ

\begin{tabular}{|c|c|c|c|c|c|c|c|c|c|c|c|c|}
\hline $\begin{array}{l}\text { Категория по } \\
\text { БНФ }\end{array}$ & Прием & $\begin{array}{l}\text { Обща } \\
\text { мед. }\end{array}$ & Кардиолог. & Респир. & $\begin{array}{l}\text { Спец. } \\
\text { мед. }\end{array}$ & $\begin{array}{l}\text { Обща } \\
\text { x-я }\end{array}$ & $\begin{array}{l}\text { Спец. } \\
\text { X-я }\end{array}$ & Ортоп. & $\begin{array}{l}\text { Гер. } \\
\text { гри- } \\
\text { жа }\end{array}$ & Други & $\begin{array}{l}\text { Общо } \\
\text { по кат. } \\
\text { по } \\
\text { БНФ }\end{array}$ & $\begin{array}{l}\% \text { по } \\
\text { кат. } \\
\text { по } \\
\text { БНФ }\end{array}$ \\
\hline $\begin{array}{l}1 \text { Гастро- } \\
\text { интестинална } \\
\text { с-ма }\end{array}$ & 177 & 68 & 40 & 13 & 5 & 46 & 29 & 23 & 32 & 5 & 438 & 10.8 \\
\hline $\begin{array}{l}2 \text { Сърдечно- } \\
\text { съдова с-ма }\end{array}$ & 415 & 139 & 150 & 32 & 8 & 130 & 78 & 86 & 83 & 21 & 1142 & 28.3 \\
\hline $\begin{array}{l}3 \text { Дихателна } \\
\text { c-ма }\end{array}$ & 178 & 102 & 42 & 28 & 2 & 31 & 36 & 23 & 26 & 19 & 487 & 12.0 \\
\hline 4 ЦНС & 272 & 105 & 58 & 6 & 7 & 58 & 37 & 66 & 57 & 16 & 682 & 16.9 \\
\hline $\begin{array}{l}5 \text { Инфекц. } \\
\text { заболявания }\end{array}$ & 15 & 6 & 3 & 7 & 0 & 7 & 6 & 5 & 6 & 10 & 65 & 1.6 \\
\hline $\begin{array}{l}6 \text { Ендокр. } \\
\text { заболявания }\end{array}$ & 142 & 57 & 26 & 6 & 3 & 19 & 36 & 27 & 28 & 6 & 350 & 8.7 \\
\hline $\begin{array}{l}7 \text { АГ и } \\
\text { уринарен } \\
\text { тракт }\end{array}$ & 23 & 2 & 3 & 2 & 0 & 8 & 8 & 6 & 2 & 2 & 56 & 1.4 \\
\hline $\begin{array}{l}8 \text { Злокач. / } \\
\text { имуносупр. }\end{array}$ & 10 & 6 & 4 & 1 & 0 & 5 & 13 & 2 & 0 & 2 & 43 & 1.1 \\
\hline $\begin{array}{l}9 \text { Хранене/ } \\
\text { хематол. }\end{array}$ & 160 & 45 & 19 & 8 & 1 & 31 & 27 & 28 & 21 & 12 & 352 & 8.7 \\
\hline $\begin{array}{l}10 \text { Опорно- } \\
\text { двиг. /ставни } \\
\text { заболявания }\end{array}$ & 47 & 23 & 13 & 6 & 2 & 18 & 16 & 18 & 10 & 2 & 155 & 3.8 \\
\hline $\begin{array}{l}11 \text { Очни забо- } \\
\text { лявания }\end{array}$ & 64 & 25 & 15 & 6 & 7 & 14 & 16 & 6 & 12 & 1 & 166 & 4.1 \\
\hline 12 УНГ & 3 & 5 & 4 & 1 & 1 & 0 & 2 & 0 & 1 & 1 & 18 & 0.4 \\
\hline $\begin{array}{l}13 \text { Дермато- } \\
\text { логия }\end{array}$ & 28 & 26 & 5 & 0 & 0 & 12 & 6 & 4 & 6 & 0 & 87 & 2.2 \\
\hline $\begin{array}{l}\text { ОБЩО } \\
\text { неволни } \\
\text { несъотв. ПО } \\
\text { ТЕРАПЕВТ. } \\
\text { ОБЛАСТ }\end{array}$ & 1534 & 609 & 382 & 116 & 36 & 379 & 310 & 294 & 284 & 97 & 4041 & 100 \\
\hline
\end{tabular}

НН под формата на пропуснати и погрешни дози за едно ЛС по терапевтични области.

В Таблица 1 е даден броят на пропуснати лекарства и погрешни дозировки за 13 категории по БНФ за всяка от оценяваните терапевтични области: Не са установени пропуснати лекарства и погрешни дозировки за продукти от категории 14 по БНФ (Имунологични продукти и ваксини) или 15 (Анестезия) (15).

Сред общия брой обекти в прегледа не са установени $\mathrm{HH}$ от IV ниво. Таблица 2 показва разпределението на НН по терапвтични области. Средно 0.52 (гранични стойности $0.21-1.18$ ) НН от трето ниво и 0.005 (гранични стойности 0.003-0.151) $\mathrm{HH}$, свързани с високорискови лекарства, са установени за общия брой разглеждани обекти. В пропорционално изражение, НН от трето ниво са $40 \%$ от всички несъответствия (между 31 и 52\% в различните терапевтични области). Дисперсионният анализ (двустранен $\mathrm{Z}$ тест) показва, че е налице доверителна вероятност над $99 \%$ различията при НН от III ниво между средната величина за общия брой разглеждани обекти и средната величина за отделните терапевтични групи да са значителни за всички групи, освен за респираторната медицина. Двустранните $\mathrm{Z}$ тестове също показват ниво на сигурност над $99 \%$ вероятността едно несъответствие от III ниво да е по-висока в отделенията „Гериатрична грижа“ и „Обща хирургия“ и да е по-ниска за пациентите от „Кардиология“ и „Обща медицина“.

Най-големият дял от НН от III ниво за повечето терапевтични области се отнася до сърдечносъдови лекарствени продукти. 260-те случая на 
Таблица 2. Анализ на неволните несъответствия (НН) по терапевтични области

\begin{tabular}{|l|l|l|l|l|l|l|l|}
\hline & \multicolumn{2}{|c|}{ Общ брой } & \multicolumn{3}{c|}{ НН от III ниво } & \multicolumn{2}{|c|}{ Грешки с високориск. л-ва (ВРЛ)† } \\
\hline Терапевт. обл. & ЛС & НН & Брой & \% Общо НН & Средно на ЛС & Брой & Средно на ЛС \\
\hline Прием на пациенти & 1062 & 1534 & 619 & 35.5 & 0.58 & 67 & 0.006 \\
\hline Обща мед. & 435 & 609 & 170 & 45.9 & 0.39 & 24 & 0.006 \\
\hline Кардиология & 302 & 382 & 112 & 31.9 & 0.37 & 19 & 0.006 \\
\hline Гериатр. грижа & 140 & 284 & 165 & 48.3 & 1.18 & 11 & 0.008 \\
\hline Дихателна с-ма & 96 & 116 & 42 & 31.0 & 0.44 & 5 & 0.005 \\
\hline Спец. медицина & 53 & 36 & 12 & 33.3 & 0.23 & 8 & 0.151 \\
\hline Обща хирургия & 292 & 379 & 191 & 44.3 & 0.65 & 15 & 0.003 \\
\hline Ортопедия & 179 & 294 & 131 & 47.2 & 0.73 & 6 & 0.003 \\
\hline Специализ. х-я & 360 & 310 & 139 & 52.3 & 0.39 & 6 & 0.016 \\
\hline Други & 167 & 97 & 35 & 36.1 & 0.21 & 1 & 162 \\
\hline Общо извадка & 3086 & 4041 & 1616 & 40.0 & 0.52 & 0.006 \\
\hline
\end{tabular}

Таблица 3. Зависимости между терапевтични области, неволни несъответствия (НН) от ІІІ ниво (умерена клинична значимост), вид на хоспитализацията (планова или спешна), редовна употреба на пет или над пет лекарства и наличие на собствени лекарства в болницата (лични лекарства, донесени от пациента)

\begin{tabular}{|c|c|c|c|c|c|c|}
\hline \multirow[b]{2}{*}{ Терапевт. област } & \multirow[b]{2}{*}{ Прегледани ЛС } & \multirow[b]{2}{*}{$\begin{array}{l}\text { Общ брой } \\
\text { установени НH }\end{array}$} & \multirow[b]{2}{*}{$\begin{array}{l}\text { Брой НH, III } \\
\text { ниво }\end{array}$} & \multicolumn{3}{|c|}{ \% от общия брой НН, свързани с } \\
\hline & & & & $\begin{array}{l}\text { Бр. записи на } \\
\geq 5 \text { л-ва* }\end{array}$ & $\begin{array}{l}\text { Спешен } \\
\text { прием† }\end{array}$ & $\begin{array}{l}\text { Хосп. пациен- } \\
\text { ти със собст- } \\
\text { вени л-ва }\end{array}$ \\
\hline Прием & 1062 & 1534 & 619 & 79 & 93 & 34 \\
\hline Обща медицина & 435 & 609 & 170 & 86 & 96 & 41 \\
\hline Кардиология & 302 & 382 & 112 & 78 & 73 & 64 \\
\hline Гериатр. грижа & 140 & 284 & 165 & 85 & 96 & 34 \\
\hline Дихателна с-ма & 96 & 116 & 42 & 85 & 77 & 59 \\
\hline Спец. мед. & 53 & 36 & 12 & 86 & 100 & 31 \\
\hline Обща хирургия & 292 & 379 & 191 & 59 & 72 & 37 \\
\hline Ортопедия & 179 & 294 & 131 & 69 & 43 & 53 \\
\hline Специализ. x-я & 360 & 310 & 139 & 65 & 27 & 61 \\
\hline Други & 167 & 97 & 35 & 66 & 62 & 60 \\
\hline
\end{tabular}

пропуснати лекарства и погрешни дози, свързани със сърдечно-съдови лекарства, установени за пациенти в сектор „Прием на пациенти“ бяха подложени на по-нататъшно изследване: $23 \%$ се отнасят до лекарства за лечение на хипертония и сърдечна недостатъчност; 18\% включват нитрати, блокери на калциевите канали и други антиангинални средства; $15 \%$ агенти за регулация на липидната обмяна; $11 \%$ агенти за блокада на бета-адренергичните рецептори; 11\% диуретици; и 10\% антитромбоцитни средства.

Общо 75\% от установените НН са за пациенти, приемащи пет и повече лекарства (между 59 и 86\% за терапевтичните области, като в 4.2\% от въпросниците липсва информация); 40\% от пациентите с НH са носели някои или всички свои лекарства от дома си в болницата (между 31 и 64\% за тера- певтичните области), а 80\% от пациентите с регистрирано НН са били хоспитализирани непланово (между 27 и 93\% за тепаревтичните области, като при $2.8 \%$ от въпросниците липсва информация) (Таблица 3).

Периодът, в рамките на който са проведени ЛС от фармацевт, варира за различните терапевтични области. Средно 65\% ЛСФ са извършени до 24 часа от приемането в болница (граница 34-83\% за тепаревтичните области, при $2 \%$ от въпросниците липсва информация). Терапевтичните области с по-висок дял ЛСФ, извършени в първите 24 часа от хоспитализацията включват: сектор „Прием на пациенти“ (73\%); „Специализирана хирургия“ (73\%), „Обща хирургия“ (70\%) и „Кардиология“ (68\%). Средно за извършването на ЛСФ за терапевтичните области са били необходими 15 минути. 


\section{Дискусия}

Неотдавнашен систематичен преглед за определяне на най-успешния метод за извършване на ЛС в болнични условия заключи, че данните са ограничени и отсъстват строго контролирани проучвания, сравняващи различните подходи за ЛС (17). Авторите установяват, че са нужни изследвания с по-високо качество, но че наличните данни са в подкрепа на интервенции, при които използването на болнични фармацевти е силно застьпено и които се насочват към пациенти с висок риск от нежелани събития (17).

Настоящото е първото мероприятие за съвместно оценяване на услуга, при което се сравняват мерките, свързани с ЛСФ за различни терапевтични области. Целта е да се използва информацията за определяне на пациенти в най-висок риск от нежелани събития, за да се укрепи и разшири базата от информация за подобрено предоставяне на услугата.

Данните, събрани от 30 обекта, сочат, че фармацевтичните екипи в реална обстановка отчитат средно 1.3 случая на НН под формата на пропуск и погрешна дозировка на едно ЛС (гранични стойности 0.6-2.1 за десет терапевтични области). Средният брой НН на един пациент, установен при това оценяване, е сходен с наблюдавания в рамките на предходна проверка със същия географски обхват (14), както и с резултатите в публикувани проучвания в определени пациентски групи (4-6). В този смисъл данните подкрепят добавената стойност, произтичаща от участието на фармацевти при изготвянето на ЛС.

Общият брой установени НН сам по себе си не дава ясна индикация за добавената стойност на ЛСФ по отношение на предотвратени нежелани събития, нито показва дали НН в някои терапевтични области могат да имат по-голямо въздействие върху лечението. Ясно е отчетено, че не всички случаи на НН, установени при ЛС, водят до нежелано лекарствено събитие (НЛС) и някои автори използват коефициент за преобразуване на несъответствията в промени в предписаните лекарства като маркер за предотвратени НЛС $(3,6)$. В настоящото оценяване на услуга за всяко несъответствие се задава ниво на потенциален клиничен ефект, а въздействие от III ниво (умерен ефект) се използва като маркер за сравняване на потенциала за предизвикване на нежелани събития.
При все че са установени някои различия между терапевтичните области, неволно причинените несъответствия с възможен умерен клиничен ефект и лекарствени грешки с висок риск се наблюдават във всички разглеждани терапевтични области. В този смисъл данните сочат, че определянето на приоритетността на предоставянето на услугата ЛСФ единствено въз основа на терапевтична област не е оптимално от гледна точка на безопасността.

Потенциалните ограничения при тази методология имат три измерения. Разгледаните ЛСФ са избрани от самите организации. Поради това е възможно подбраните терапевтични области вече да са определени като приоритетни от организацията за получаването на услугата ЛСФ. Независимо от това ограничение, като цяло оценените ЛСФ покриват разнообразни терапевтични области, което позволява сравнимост на резултатите за различните области.

Другите два ограничаващи момента са свързани с това, че категорията клиничен ефект за НН не е предмет на вътрешна ревизия и коефициентът за преобразуване на НН в промени в предписаните лекарства не е отчитан. Независимо от това критериите за и дельт на НН, за които в настоящото оценяване е решено, че потенциално могат да нанесат умерена вреда, са сходни с тези от проучвания, в които клиничната значимост е била предмет на вътрешно удостоверяване, $(3,4,6)$ и определянето на степени се потвърждава от наблюдението, че $80 \%$ от установените НН от III ниво са за лекарства от четири групи по БНФ, свързани основно с управлението на дълготрайни заболявания (Таблица 1): сърдечно-съдови (39\%), ЦНС (17\%), ендокринни $(14 \%)$ и респираторни $(9 \%)$. Тези четири категории лекарства съставляват $64 \%$ от предписаните средства в условията на първична грижа в Англия през 2010 г. (18). Проучвания открояват и високи нива на НН за лекарства за заболявания на съдечно-съдовата и централната нервна система (4-6).

\section{ФАКТОРИ, ОКАЗВАЩИ ВЛИЯНИЕ ВЪРХУ ТОЧНОСТТА НА ЛС НА ЕТАП ХОСПИТАЛИЗАЦИЯ}

Ако сам по себе си признакът „терапевтична област" не е надежден критерий за определяне на приоритет за кои пациенти да се прави ЛС, би било целесъобразно да се използват други фактори за по-прецизно определяне на приоритетността. Като рискови фактори по отношение на лекарствените грешки при постъпването на пациенти в болница 
се посочват напредналата възраст и по-големият брой предписани лекарства, както и това, че представянето на списък от лекарства или физическото им наличие е фактор за избягване на грешки $(6,17)$.

Въпреки че в настоящото оценяване на услуга не се отчитат възрастта на пациента и броят предписани лекарства, пациентите са отнесени към една от две групи: с четири и по-малко или с пет и повече лекарства. Над 75\% (с гранични стойности 59-86\%) от всички НН от III ниво са за пациенти с пет и повече лекарства. Важно е обаче да се отчете, че над $20 \%$ от НН от III ниво (с гранични стойности 14-41\%) са при пациенти на пет и по-малко лекарства. Cornish et al (4) след изследване на пациентите са продължили с ЛСФ единствено когато пацинетьт съобщава, че приема четири или повече лекарства. Данните от настоящото оценяване на услуга биха могли да индикират, че определянето на приоритетността за ЛС въз основа на броя редовно приемани лекарства също има своите ограничения с оглед гарантирането на безопасността на пациентите.

Тази оценка на ЛСФ е първата, включваща голям брой пациенти, хоспитализирани планово, предимно за операция по желание. Плановата хоспитализация потенциално благоприятства прецизното ЛС в момента на приема, тъй като такива пациенти обикновено посещават клиника за подготовка на приема, при което се снема подробна анамнеза и обикновено им се казва да носят със себе си в болницата лекарствата, приемани редовно. Но данните от настоящото проучване показват, че групите пациенти с най-висока норма на планиран прием (специализирана хирургия и ортопедия) са със сходни или по-високи нива на НН от III ниво в сравнение с терапевтичните области с предимно непланови хоспитализации. Нещо повече: над 40\% от пациентите с НН от Трето ниво носят редовно приеманите лекарства със себе си в болницата, независимо дали хоспитализацията е планова или не, което индикира, че здравните работници, приемащи пациентите, вероятно не използват оптимално наличната информация относно лекарствата, когато назначават лечение при приема.

Едно подобрено работно взаимодействие между специалисти от различни професионални области в процеса на прием на пациенти, постьпващи по свое желание, би могло да е от ключово значение за повишаване на безопасността на пациентите и за оптимизирането на услугите, свързани с ЛСФ. Качествен анализ на причините за грешки при назначаването на лекарства, допускани от младши лекари в Англия показва липса на „култура на безопасността“" сред младите специалисти, предписващи лекарствени продукти, като лекарите разчитат извънредно много на фармацевтите и сестрите за откриване и поправяне на грешките (1) Неотдавнашно проучване изследва пречките по отношение на ЛС, свързани с възприятията на здравните специалисти (19). Полуструктурирани интервюта показаха, че в средите на интервюираните лекари, сестри и фармацевти няма достатъчно познаване на този проблем в здравеопазването и на решението му. Също така се видя, че някои клинични специалисти не са убедени в ползите от ЛС, предвид факта, че доказателствата в полза на прилагането му са минимални (19). Сред другите пречки са неясното разпределение на задължения, като специалистите нямат ясно и единно разбиране относно задълженията и отговорностите, в съчетание с липсата на обратна информация относно изпълнението. Това води до различни подходи при извършването на ЛС в рамките на една организация и дублиране на дейности, като например снемане на историята на приеманите лекарства. Изводът на авторите е, че е необходим мултидисциплинарен план за извършването на дейностите за оптимизиране на ползите за безопасността на пациентите (19).

Подобреното разбиране на важността на прецизното ЛС в момента на хоспитализацията от страна на медицинския персонал, извършващ приема, заедно с обучение и подкрепа за най-добрите начини за гарантиране на прецизност на ЛС и указания кога да се търсят фармацевти може да е ключов инструмент за оптимизиране на ЛС при приема, в частност в области, за които лекарствата или лекарствените списьци са на разположение. Подобен подход може да се окаже по-удачен от процеса на определяне на приоритетност, провеждан единствено от болнични фармацевти въз основа на предварително определени критерии.

За някои групи пациенти, например пациенти, постьпващи в болница по свое желание, ресурсите на болничните фармацевти също могат да се използват по-оптимално за осигуряване на прецизно предписване на лекарства при хоспитализацията чрез образование и обучение, вместо чрез провеждане на ЛС от самите фармацевти. Предлага се използването на стандартен формуляр (на хар- 
тиен носител или в електронен вид) за събиране на необходимите сведения като средство в подкрепа на съгласуването, като това може да е успешна стратегия в различни условия, по-специално на етап подготовка на болничния прием (5,20-23). Също така организациите биха могли да разгледат възможността за въвеждане на политика, гарантираща приоритет на ЛСФ за пациенти, приемащи лекарства, които се водят високорискови, като лекарствени продукти, изискващи предупреждения относно безопасността (16).

Прецизното ЛС не е отговорност единствено на здравните професионалисти, които приемат пациентите: самите пациенти също следва да бъдат насърчавани да изпълняват своята роля. Много пациенти, постьпващи в болница в Англия, се срещат с редица здравни специалисти в хода на лечението на хронични или остри заболявания. Както и в други страни по света, невинаги може да се разчита на точното предаване на информация за лекарствата с помощта на електронни или хартиени средства, а пациентите, когато постьпват в болница, може да не са в състояние да пояснят различни въпроси, свързани с лекарствата, които приемат или може да не са достатъчно медицински грамотни, за да го направят. В този смисъл е необходимо да се гарантира пациентите да имат по всяко време актуален списьк на всички свои лекарства (с и без рецепта). Това следва да е с подкрепата на здравните професионалисти (22) и да се подпомага с разяснителни кампании. Пациентите могат също да бъдат съветвани винаги да носят със себе си лекарствата, които приемат редовно, когато постьпват в болница.

\section{ОПРЕДЕЛЯНЕ НА ПОЛЗИТЕ, СВЪРЗАНИ С ЛС ОТ ФАРМАЦЕВТИ}

Ползите от прецизното ЛС към момента са недооценени от страна на здравни специалисти и ръководители на здравни заведения (18). По-доброто споделяне на ползите, свързани с безопасността на пациентите и икономическите ползи за здравните заведения по места, ведно с обратна информация за осъществяването на дейностите, може да е поуспешно за повишаване на качеството на ЛС в сравнение с решения за реализиране на услугата чрез актове на национално ниво или на ниво отделна организация.

Изследвания се опитват да дадат количествено изражение на клиничното въздействие на прецизното ЛС върху грижите за пациентите. Boockvar et al установяват, че с използването на компютъризирано ЛС и процедура за болничен прием, ЛС намалява възможните нежелани лекарствени събития в неспециализираните отделения с 43\% (24). През 2007 г. Karnon et al провеждат систематичен преглед на интервенциите за предотвратяване на лекарствени грешки при хоспитализация, за извеждането на модел, който да послужи за основа на указания за ЛС за Великобритания (11) В този модел се изчислява изходен показател от 2.8 (1.54.5) потенциални нежелани лекарствени събития на 1000 рецепти, изписани при хоспитализация, като 75\% от тези събития могат да се избегнат с помощта на ЛСФ, а 50\% - с помощта на систематичен подход или участие на помощник-фармацевт. Тези изчисления са въз основа на данни за възможни нежелани лекарствени събития от редица изследвания.

Чрез прилагането на модела, изведен от Karnon et al спрямо събраните данни в това мащабно оценяване на услуга, обхващащо 3086 пациенти и с допускане на средно 5 предписани продукта на пациент при хоспитализация, може да се очакват приблизително 43 (при гранични стойности 23-69) възможни нежелани лекарствени събития за болничния престой за тази група пациенти, като между 22 и 33 случая (при гранични стойности 11-52) могат да бъдат предотвратени с ЛС, в зависимост от това дали ЛСФ е с участието на фармацевти или помощник-фармацевти (11).

Горните изчисления се отнасят само до възможни нежелани лекарствени събития за болничния престой. Неволен пропуск на лекарства за хронични заболявания за времето на болничния престой и след това при изписването на пациента, може да накара следващият специалист, предписващ лекарства, да приеме, че пропускането е умишлено. Дълготрайно пропускане на лекарство за хронично заболяване така може да доведе до потенциално нежелано лекарствено събитие след изписването на пациента. Bell et al са провели проучване на демографска основа с обособени групи, обхващащи 396380 пациенти на възраст 66 г. и повече, използващи продължително време лекарства, за които има налични данни (статини, антитромбоцитни и противосъсирващи средства, левотироксин, респираторни инхалатори и средства за намаляване на стомашната киселина) (7). Авторите установяват, че пациентите, постъпили в болница, са изложени на по-висок риск от възможно неволно спиране 
на лекарства в сравнение с контолните групи и че при пациентите, проследявани в продължение на 1 година с преустановен прием на статини или антитромбоцитни или противосъсирващи средства е повишена стойността на коригирано съотношение на шансовете за показатели за вторични съставни събития за изход за смърт, търсене на спешна помощ или хоспитализация (7).

\section{Изводи}

Настоящото мащабно оценяване на услуга в реални условия показва, че ЛСФ установява средно 1.3 неволни несъответствия, свързани с предписване на лекарства за един пациент, като така потенциално се предотвратява приблизително едно нежелано събитие с клинична значимост на 100 проведени ЛС.

Въпреки че несътоветствия, които могат да причинят умерена вреда, се установяват по-често за определени терапевтични области в сравнение с други такива, те съставляват най-малко 30\% от общия брой несъответствия за всички разглеждани терапевтични области. Също така несътоветствия, свързани с високорискови лекарства, се установяват за всички терапевтични области. Тези резултати показват, че определянето на приоритетност на услугите ЛСФ на база терапевтична област не може да се препорьча с оглед гарантиране на сигурността на пациента.

Настоящото оценяване на услуга индикира, че нито физическата наличност на лекарство на пациент, нито факторьт ,планова хоспитализация“ не повишават прецизността на назначаването на лекарства при болничен прием и не намаляват дела на неволни несъответствия при предписване на лекарства, които са с възможен умерен клиничен ефект при лечението на пациента.

Трудностите, свързани с прилагането на прецизно ЛС при болничен прием, независимо от актове в глобален план, които утвърждават неговата важност и наложителност, подчертават необходимостта организациите да преосмислят своите действащи политики и процедури при прием на пациенти и да насърчават мултидисциплинарен, интегриран подход за извършване на прецизно ЛС в цялата организация. В частност, следва да са ясни задълженията и отговорностите на всички здравни професионалисти. Докато [болничните] фармацевти не са достатъчно на брой за своевременното извършване на ЛСФ за всички пациенти, ролята на болничните фармацевти трябва да се преориентира - от снемането на изчерпателни данни за приеманите лекарства за всички пациенти, което улеснява ЛС, към обучение и подкрепа за лекари и сестри за прецизно снемане на тези данни и търсене на фармацевти за съдействие само при необходимост. Въвеждането на непрекъсната работна практика седем дни в седмицата също може да даде ценни възможности за по-ефективно включване на своевременно извършване на ЛС в грижата за пациентите.

\section{Основни ПоСЛАНия}

- Какво е вече известно по темата

- Лекарственото съгласуване (ЛС) при промяна на формата на грижа за пациента е императив по отношение на безопасността на пациентите в много държави.

- Данните сочат, че прецизното ЛС в момента на прием в болница е с най-висока ефективност на разходите, когато се извършва от екип от болнични фармацевти.

- Фармацевтичните звена в много болници не разполагат с ресурсите за своевременно изготвяне на ЛС на всички приемани пациенти. В резултат на това ръководителите на фармацевтичните звена в болниците определят приоритети по отношение на терапевтичните области, в които да се извършват ЛС въз основа на преценка за потенциални ползи за пациентите.

• Каква добавена стойност носи изследванеT0

- Настоящото съвместно оценяване на услуга, обхващащо 30 болници установи сходни нива на грешки при предписването на лекарства с потенциално умерено клинично въздействие, допускани във всички разглеждани терапевтични области, което показва, че определянето на приоритети единствено на принципа на терапевтична област не е вариант, гарантиращ безопасност.

- Предлагат се алтернативни стратегии. Всички стратегии следва по-оптимално да използват наличната информация на етап прием в болница.

\section{БЛАГОДАРНОСТИ}

Изказва се благодарност на: Кристин Мастерсън за нейната работа при интегрирането и обработката на данните; Греъм Додс, Mmath, за неговата помощ и съвети за използването на статисти- 
ческите тестове; болниците за активно лечение в Източна и Югоизточна Англия за събирането на сведения с помощта на въпросници на пилотна база и за приноса им под формата на данни за оценяването на услугата.

\section{БЕЛЕЖКИ ПОД ЛИНИЯ}

- Конкуретни интереси - не са налице.

- Удостоверяване на източници и вътрешна рецензия - не е възлагано; проведена е външна рецензия.

- Заявление относно споделянето на данни: Наличните данни биха могли да бъдат предоставяни при заявка до автора.

\section{ИЗПОЛЗВАНИ ИЗТОЧНИЦИ}

1. Dornan T, Ashcroft D, Heathfield H, et al. An in depth investigation into causes of prescribing errors by foundation trainees in relation to their medical education. EQUIP study. Final report. http://www.gmc-uk.org/about/research/ research_commissioned_4.asp (accessed 8 Aug 2013).

2. Tam VC, Knowles SR, Cornish PL, et al. Frequency, type and clinical importance of medication history errors at admission to hospital: a systematic review. Can Med Assoc J 2005;173:510-15.

3. Vira T, Colquhoun M, Etchells E. Reconcilable differences: correcting medication errors at hospital admission and discharge. Qual Saf Health Care 2006;15:122-6.

4. Cornish PL, Knowles SR, Marchesano R, et al. Unintended medication discrepancies at the time of hospital admission. Arch Intern Med 2005; 165:424-9.

5. De Winter S, Spriet I, Indevuyst $\mathrm{C}$, et al. Pharmacistversus physician-acquired medication history: a prospective study at the emergency department. Qual Saf Health Care 2010;19:371-5.

6. Gleason KM, McDaniel MR, Feinglass J, et al. Results of the medications at transitions and clinical handoffs $(\mathrm{MATCH})$ study: an analysis of medication reconciliation errors and risk factors at hospital admission. J Gen Intern Med 2010;25:4417 .

7. Bell CM, Brener SS, Gunraj N, et al. Association of ICU or hospital admission with unintentional discontinuation of medications for chronic diseases. J Am Med Assoc 2011;306:840-7.

8. Bell CM, Bajcar J, Bierman AS, et al. Potentially unintended discontinuation of long-term medication use after elective surgical procedures. Arch Intern Med 2006;166:2525-31.

9. Institute for Healthcare Improvement. Medicines reconciliation at all transitions. http://app.ihi.org/imap/ tool/\#Process=7ce51016-b4f0-423c-9f8b-5e1ea8d7b810 (accessed 8 Aug 2013).

10. National Institute for Health and Clinical Excellence. PSG001 Technical patient safety solutions for medicines reconciliation on admission of adults to hospital. 12 December 2007. http://guidance.nice.org.uk/PSG001/Guidance/doc/English (accessed 8 Aug 2013).
11. Karnon J, Campbell F, Czoski-Murray C. Model-based cost-effectiveness analysis of interventions aimed at preventing medication error at hospital admission (medicines reconciliation). J Eval Clin Prac 2009;15:299-306.

12. Greenwald JL, Halasyamani L, Greene J, et al. Making inpatient medication reconciliation patient centred, clinically relevant and implementable: a consensus statement on key principles and necessary first steps. J Hosp Med 2010;5:47785.

13. Dodds L. The time-scale for delivery of pharmacy-led medicines reconciliation: results of a collaborative audit across East and South East England. Int J Pharm Prac 2010;18(Suppl 2):41-2.

14. Dodds L. Unintended discrepancies between pre-admission and admission prescriptions identified by pharmacy-led medicines reconciliation: results of a collaborative service evaluation across east and South East England. Int J Pharm Prac 2010;18(Suppl 2):9-10.

15. British Medical Society \& Royal Pharmaceutical Society. British National Formulary 58 September 2009. Basingstoke, UK: Pharmaceutical Press. http://www.pharmpress.com

16. National Patient Safety Agency. National Reporting and Learning Service. http://www.nrls.npsa.nhs.uk (accessed 8 Aug 2013).

17. Mueller SK, Sponsler KC, Kripalani S, et al. Hospital-based medication reconciliation practices. A systematic review. Arch Intern Med 2012;172:1057-69.

18. The Information Centre for Health and Social Care. Prescription cost analysis England 2010. http://www.ic.nhs. uk/webfiles/publications/007_Primary_Care/Prescribing/ Prescription_Cost_Analysis_England_2010/Prescription Cost_Analysis_2010.pdf (accessed 10 Jan 2012).

19. Van Sluisveld N, Zegers $M$, Natsch $S$, et al. Medicine reconciliation at hospital admission and discharge: insufficient knowledge, unclear task reallocation and lack of collaboration as major barriers to medication safety. BMC Health Serv Res 2012;12:170.

20. Tschantz Unroe K, Pfeiffenberger T, Riegelhaupt S, et al. Inpatient medication reconciliation at admission and discharge: a retrospective cohort study of age and other risk factors for medication discrepancies. Am J Geriatr Pharmacother 2010;8:115-26.

21. Varkey P, Cunningham J, O`Meara J, et al. Multidisciplinary approach to inpatient medication reconciliation in an academic setting. Am J Health Syst Pharm 2007;64:850-4.

22. The Royal Pharmaceutical Society. Keeping patients safe when they transfer between care providers- getting the medicines right. Good practice guidance for healthcare professionals. July 2011. http://www.rpharms.com/gettingthe-medicines-right/professional-guidance.asp (accessed 10 Jan 2012).

23. Schnipper JL, Hamann C, Ndumele CD, et al. Effect of an electronic medication reconciliation application and process redesign on potential adverse events. Arch Intern Med 2009;169:771-80.

24. Bookvar KS, Blum S, Kugler A, et al. Effect of admission medication reconciliation on adverse drug events from admission medication changes (research letter). Arch Intern Med 2011;171:860-1. 
$\fallingdotseq$ Адрес за кореспонденция: Linda J Dodds,

Medicines Use and Safety Division,

East and South East England Specialist

Pharmacy Services,

Clinical Pharmacy Unit,

Northwick Park Hospital,

Watford Road, Harrow HA1 3UJ, UK;

Linda.Dodds@nhs.net 